\title{
Novel Method for Analyzing Crack Growth in Polymeric Microtensile Specimens by In Situ Atomic Force Microscopy
}

\author{
Journal Article \\ Author(s): \\ Lang, U.; Suess, T.; Wojtas, N.; Dual, Jürg \\ Publication date: \\ 2010 \\ Permanent link: \\ https://doi.org/10.3929/ethz-b-000016956
}

Rights / license:

In Copyright - Non-Commercial Use Permitted

Originally published in:

Experimental Mechanics 50(4), https://doi.org/10.1007/s11340-009-9240-y 


\title{
Novel Method for Analyzing Crack Growth in Polymeric Microtensile Specimens by In Situ Atomic Force Microscopy
}

\author{
U. Lang $\cdot$ T. Süss $\cdot$ N. Wojtas $\cdot$ J. Dual
}

Received: 22 May 2008 / Accepted: 23 February 2009 / Published online: 27 March 2009

(C) Society for Experimental Mechanics 2009

\begin{abstract}
In this paper a micro tensile test which allows the determination and observation of the crack growth behaviour in thin polymer layers is presented. The setup consists of micromanipulators and piezo actuators for straining the sample while an atomic force microscope (AFM) is used for scanning the crack tip area with high lateral resolution. The stress in the specimen is determined by an optical microscope for observation of the deflection of a force sensing beam. The material under investigation is an amorphous and strongly entangled thermoplastic polyimide which can be patterned photolithographically and is spin cast to form layers of $3 \mu \mathrm{m}$ thickness. The results show the potential of the setup to measure crack length, crack tip opening and nominal stress. The stress-crack lengthdiagram then allows to determine different stages during crack growth.
\end{abstract}

Keywords Polyimide $\cdot$ Tensile testing $\cdot$ In situ $\cdot$ AFM

U. Lang $(\varangle) \cdot$ T. Süss · N. Wojtas · J. Dual

Center of Mechanics-Department of Mechanical and Process Engineering, ETH Zurich, Tannenstr. 3, 8092 Zurich, Switzerland

e-mail: udo.lang@alumni.ethz.ch

\section{Introduction}

Crack initiation and growth are key issues when it comes to the mechanical reliability of microelectronic devices and microelectromechanical systems (MEMS). Especially in organic electronics where flexible substrates will play a major role these issues will become of utmost importance. It is therefore necessary to develop methods which allow the experimental investigation of fracture processes in thin organic layers as mechanical failure of devices is usually accompanied by crack propagation. Since polymers are often amorphous, non conductive and cannot withstand the electron beam of electron microscopes for a long time, the approach herein is therefore based on the use of an AFM to determine in situ crack propagation during straining of a polymer specimen. Similar setups have been used to examine silicon [1-7], thin metal films on polymer substrates [8-10] and pure polymer samples [11-18]. In contrast to those approaches, in the experiments presented here, the force measurement is integrated in the microfabricated samples as presented by Haque and Saif in [19]. This technique allows to investigate thin samples with micrometer thickness and to measure forces in the range of millinewtons. By using an optical microscope the deformation of a silicon force sensing beam can be observed and by applying beam mechanics the force acting on the specimen can be determined (Fig. 1). The tensile samples in this research are made from the polyimide PI 2723 from HD Microsystems (Wilmington, DE, USA). Polyimide was chosen because it is widely used as a passivation layer to protect microelectronic devices from moisture and corrosion. Additionally, polyimides are often used as stress buffer layers during packaging of dies [20]. Moreover, 


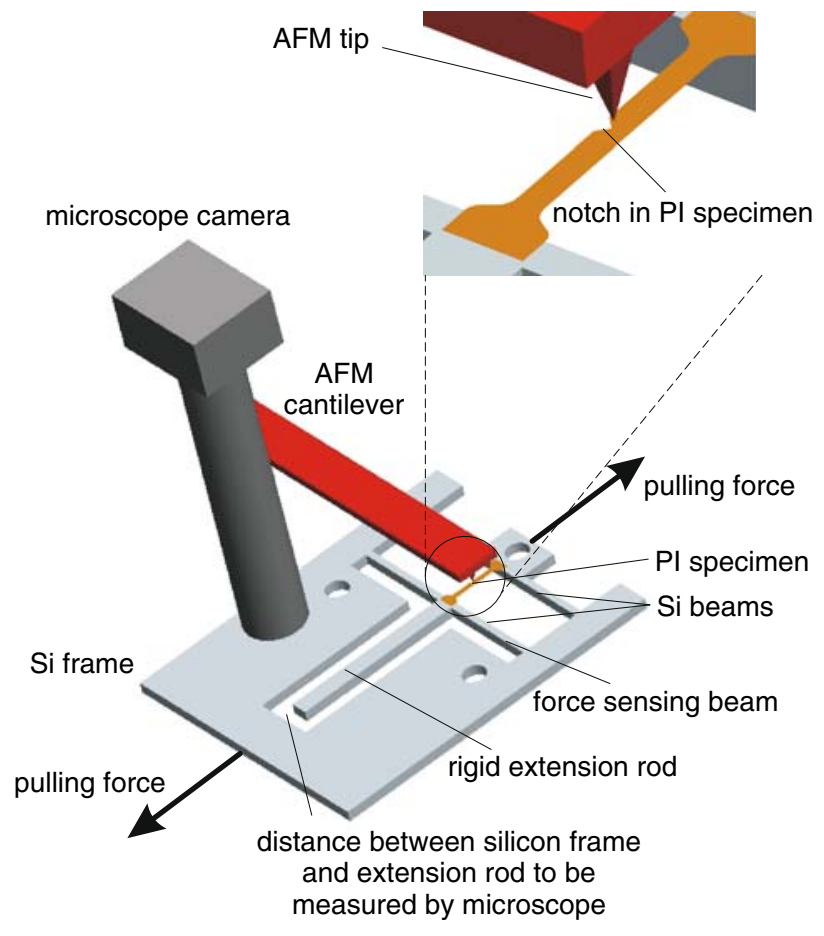

Fig. 1 Principle of the setup: the specimen is strained between two silicon beams while crack growth is monitored in situ by an AFM. A photolithographically structured notch results in a locally well defined crack initiation. The deformation of a force sensing beam is determined by an optical microscope. The rigid extension rod is necessary because the actual force sensing beam is hidden underneath the AFM. The three pin holes in the $\mathrm{Si}$ frame are used for force transmission by small pins from the external piezo actuators to the specimen

polyimides are promising candidates for flexible substrates in organic electronics [21,22] and in the MEMS community as a membrane material [23-25].

\section{Experimental}

\section{Specimens}

The specimen itself consists of a freestanding $3 \mu \mathrm{m}$ polyimide PI 2723 tensile probe and a silicon frame. They are both shown in Fig. 2 with dimensions. Connected to one of the silicon beams there is an extension rod which can be considered a rigid body. Based on this assumption, the deformation of the silicon force sensing beam is transferred directly to this extension rod. Therefore the deflection of the beam can be determined by measuring the distance between the extension beam and the rigid silicon frame. This is necessary because the actual force sensing beam is hidden behind the AFM and can therefore not be monitored directly. The geometry of the PI tensile probe is based on an international norm on tensile tests of polymers [26] with an additional single notch on one side. The fabrication of the specimens is mainly based on the Bosch deep dry etching process and is explained in [27] in detail. The polyimide used in these experiments is PI 2723 as mentioned before. It is photodefinable and can be applied by spin coating. It is therefore also very suitable for MEMS applications. Its morphology shows a very amorphous structure caused by a strong entanglement of the chains (Knaus, M, HD Microsystems Europe, Neu-Isenburg, Germany, personal communication, October 2008). As its glass transition temperature is rather high $\left(>320^{\circ} \mathrm{C},[20]\right)$ and the tests are conducted at room temperature, the thermoplast will be in its glassy state and therefore one can expect a rather brittle and very limited viscous behaviour (a)

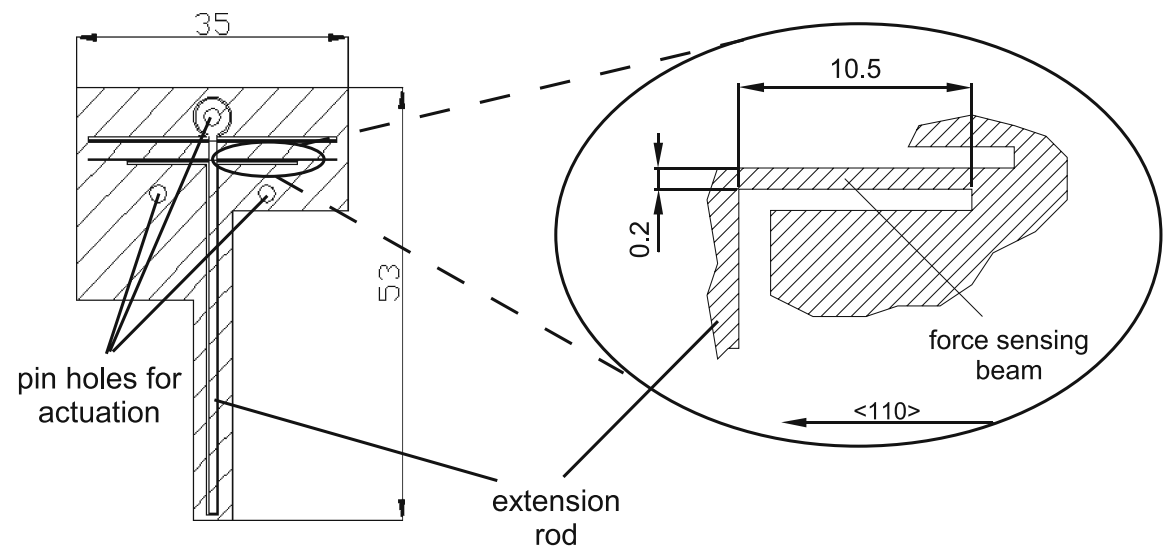

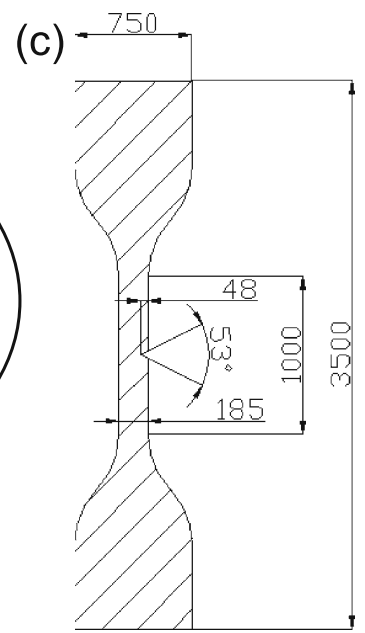

Fig. 2 Dimensions of setup: (a) shows the overall size of the specimen and of the extension rod (in mm), (b) shows the dimensions of the silicon force sensing beam (in $\mathrm{mm}$ ) and its orientation on the wafer and (c) shows the dimensions (in $\mu \mathrm{m}$ ) of the polyimide specimen including the notch. The thickness of the silicon (100) wafer is $525 \mu \mathrm{m}$. The thickness of the PI specimen is $3 \mu \mathrm{m}$ 
[28-30]. This behaviour has indeed already been shown in [31] for polyimide (Kapton) films. As PI 2723 is even more entangled than Kapton tape (Knaus, M, HD Microsystems Europe, Neu-Isenburg, Germany, personal communication, October 2008) one could therefore assume that viscous effects and the size of the plastic zone in front of the crack tip will be limited in size.

\section{Atomic Force Microscope}

An easyScan AFM (Nanosurf AG, Liestal, Switzerland) was used in the experiments. Its main characteristics are a maximum scan range of $100 \mu \mathrm{m}$ in $\mathrm{x}$ - and $\mathrm{y}$ - directions and of $20 \mu \mathrm{m}$ in $\mathrm{z}$ - direction. In actual experiments the lateral scan range was set to $60 \mu \mathrm{m}$ at a sampling rate of 256 which yielded a resolution in $\mathrm{x}$ - and $\mathrm{y}$ - direction of $0.23 \mu \mathrm{m}$. For such an area a scan usually takes about 3 minutes. Scans are typically taken in contact mode and closed loop control with a load of $11 \mathrm{nN}$ and automatic z-offset adjustment. The cantilevers were of type Contr-16 (Nanosensors AG, Neuchâtel, Switzerland) and had a typical tip diameter of less than $10 \mathrm{~nm}$ and a tip height of about $10-15 \mu \mathrm{m}$.

\section{Detection of Forces}

\section{Mechanics of force sensing beam}

The principle used herein for measuring forces is based on the deformation of single crystal silicon double fixed beams and was first presented by Haque and Saif in [19]. As shown in Fig. 1 the application of an external force on the first beam leads to the deformation of that beam, to the straining of the specimen and to the deformation of the second force sensing beam.

The calculation of a force causing large deflections of double fixed beams was first presented by Frisch-Fay [32] in detail. Here, a brief summary of his explanations only as far as necessary to understand the train of thought is given. The main idea is that when such a beam with two fixed ends undergoes a large deflection, then also normal forces will develop in axial direction. It should be emphasized that large deflections in this context mean that normal forces develop in the beam, but that the actual deflection in the middle is small compared to the overall length of the beam. Figure 3 shows a beam which is loaded with a force of $2 P$ and the corresponding free body diagram. Contrary to first order theory the equilibrium is derived from the deflected state. This leads to an additional moment $N y$.

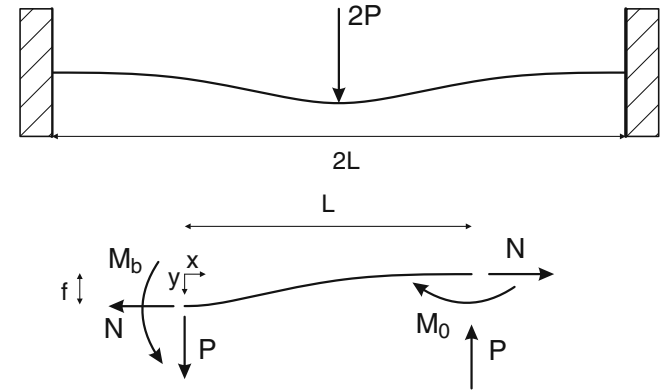

Fig. 3 Deformation of double fixed beam under a load of $2 P$ and corresponding free body diagram

Equilibrium of moments at an arbitrary point $x$ along the half of the beam therefore is:

$$
\begin{aligned}
M_{b} & =E I \frac{\mathrm{d}^{2} y}{\mathrm{~d} x^{2}} \\
& =N y+M_{0}-P(L-x)
\end{aligned}
$$

where $M_{b}$ is the bending moment at position $x, E$ is Young's Modulus of the beam material and $I$ the moment of inertia of the beam for bending about the $\mathrm{Z}$ - axis. The general solution of equation (1) is

$y=C_{1} \cosh t x+C_{2} \sinh t x+A x+B$

where $C_{1}$ and $C_{2}$ have to be found from boundary conditions for a double fixed beam and from beam symmetry, while $A=-P / N, B=\left(P L-M_{0}\right) / N$ and $t=\sqrt{(N / E I)}$ can then be found from comparing coefficients in equation (2) and equation (1). Considering the axial extension of the beam caused by the constant normal force $N$ (for small slopes) and some additional calculus yields an equation for $N$ :

$N^{3}=\frac{A_{c} E P^{2}}{2}\left[\frac{3}{2}-\frac{1}{2} \tanh ^{2} u-\frac{3}{2} \frac{\tanh u}{u}\right]$

with $u=t L / 2$ and $A_{c}$ as the cross sectional area of the beam. Solving equation (3) for $P$ yields

$P=\sqrt{\frac{2 N^{3}}{A_{c} E}}\left(\frac{3}{2}-\frac{1}{2} \tanh ^{2} u-\frac{3}{2} \frac{\tanh u}{u}\right)^{-\frac{1}{2}}$.

Using equations (2) and (4) and calculating the value of $y(x)$ at $x=0$ (middle of the beam) leads to

$$
\begin{aligned}
& f=2 \sqrt{\frac{2 I}{A_{c}}}(u-\tanh u) . \\
& \left(\frac{3}{2}-\frac{1}{2} \tanh ^{2} u-\frac{3}{2} \frac{\tanh u}{u}\right)^{-\frac{1}{2}}
\end{aligned}
$$


which is the desired relation between $P$ and the deflection $f$ at the middle of the beam. For $f$ given from the experiment, equation (5) is numerically solved for $u$. $P$ is then obtained from equation (4) using $u=$ $t L / 2$ and $t=\sqrt{(N / E I)}$. This calculation can be easily programmed with any numerical computing program e.g. Mathematica or Matlab. In these experiments a simple Matlab code was used to calculate $P$ from the measured deflection $f$. The maximum stress due to bending then develops at the fixed ends of the beam and is given by

$\sigma_{\max }=\frac{1}{3} E\left(\frac{h}{L}\right)^{2} u^{2}$.

$\left[1+\sqrt{6} \tanh u\left(\frac{3}{2}-\frac{1}{2} \tanh ^{2} u-\frac{3}{2} \frac{\tanh u}{u}\right)^{-\frac{1}{2}}\right]$

where $h$ is the height of the beam, in this case $200 \mu \mathrm{m}$ (see Fig. 2). Assuming a yield strength of $7 \mathrm{GPa}$ and a Young's modulus of $169 \mathrm{GPa}$ for silicon in $<110>$ direction [33], a theoretical maximum detectable force $P$ of $\approx 60 \mathrm{~N}$ can be obtained from equation (4). The optical system (see "Measurement of beam deflection and crack growth") permits a resolve limit of about $1 \mu \mathrm{m}$ which yields with equations (4) and (5) a force resolution of about $0.0012 \mathrm{~N}$.

\section{Measurement of beam deflection and crack growth}

Measuring the actual displacement of the extension rod during experiments was done by an high magnification zoom lens $(1 \times-12 \times)$ (Navitar Inc., Rochester, USA) with a 2 megapixel CCD camera (Moticam 2000, Motic Deutschland GmbH, Wetzlar, Germany) attached to it (see Fig. 1). For every AFM scan also a image of the extension rod was taken. The rod displacement was then determined by carefully measuring the distance between the rod and the frame using the image analysis program Motic Images Plus 2.0. This program allows to determine lateral dimensions with its distance tool. Before measurements the program was furthermore calibrated using a distance normal. The actual measurements were then conducted by determining the normal distance between the easily identifiable corners of the extension rod and the frame and then calculating the mean. Motic Images Plus 2.0 was also used to determine crack length. For this, the AFM scans were carefully analyzed by determining the distance from the bottom of the notch to the tip of the crack (see also Section "Results"). microscope camera

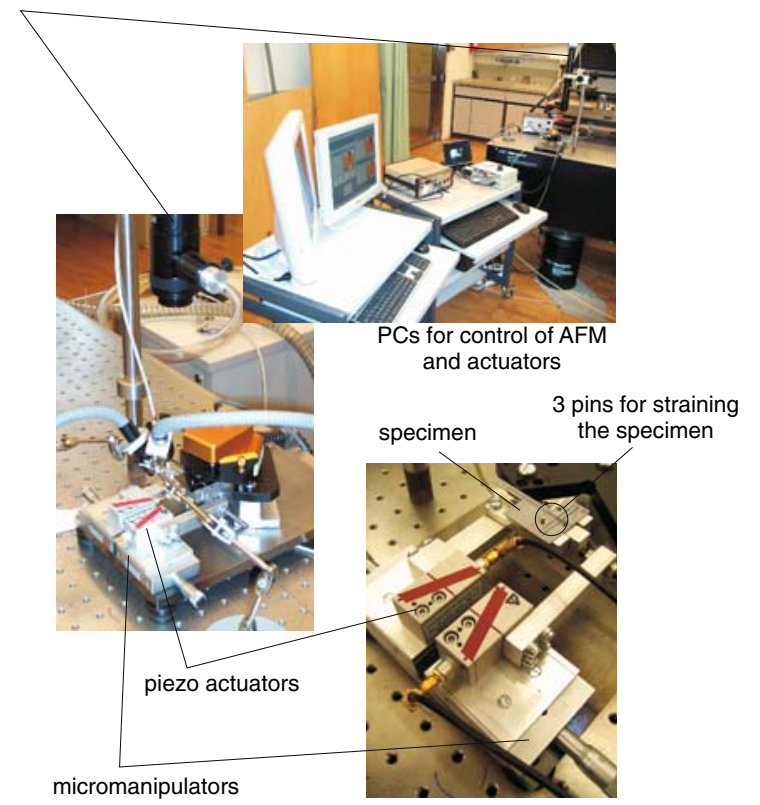

Fig. 4 Experimental setup. Two micromanipulators and two piezo actuators are used. They point pairwise into opposite directions which results in larger maximum displacements. Furthermore the notch area can thus be kept in a central position

\section{Actuation and Control}

Figure 4 shows the actual setup. For the experiments the samples are put on the pins which transfer the motion generated by the micromanipulators and piezo actuators (model P-280, $100 \mu \mathrm{m}$ range, PI GmbH, Karlsruhe, Germany) to the specimens. The micromanipulators are necessary to bring the pins in contact with the specimen to make sure that the whole range of the piezo actuators can be used for precisely straining the specimen. An actual experiment is conducted stepwise: the specimen is strained for approximately $5 \mu \mathrm{m}$ whereat this overall displacement is composed of two displacements of $2.5 \mu \mathrm{m}$ pointing in opposite directions. The region of interest i.e. the notch thus remains in principle unmoved. Then an AFM scan and a image of the extension rod are taken. Then the specimen is strained for an additional $5 \mu \mathrm{m}$ and again scans and images are taken and so forth until rupture of the sample. The whole experiment is therefore controlled by actuator displacements. During manual actuation it might happen that the two micromanipulators are not actuated exactly the same way and thus the crack might be moved away from the central position of the AFM scan. This can then be accounted for in the AFM scan software by readjusting the scan area without adverse effects on the samples. 


\section{Results}

Two specimens were tested at $23^{\circ} \mathrm{C}$ and $25 \%$ relative humidity. For both samples the surface roughness $R_{a}$ was about $30 \mathrm{~nm}$. From scan to scan no changes in the surface quality could be observed. Hence it can be concluded that the material was not damaged by the AFM tip and therefore the contact force was not too large. It was mentioned before that due to the strong entanglement of the polymer chains in PI 2723 only very limited viscous effects had to be expected. This could be confirmed as during the considerably long time of several minutes for a single scan no smearing or reflow in the scan area could be observed. Furthermore, the results are very similar for both of the tests as can be seen from Fig. 5 which shows the nominal stress within the sample far enough away from the notch (i.e. the stress is calculated for a width of $185 \mu \mathrm{m}$ ) versus the crack length starting from the bottom of the notch. To relate the stress-crack length diagram to actual rupture processes, different stages of the crack propagation through the sample are identified in Fig. 6. The scans in Fig. 7 then show corresponding AFM scans for these different stages of crack growth. Especially from the images of column II, it can also be seen that the crack does not extend all the way through the thickness of the specimen but reaches from the surface at the bottom of the notch into the material. It can therefore also be regarded as a surface crack starting at the notch and extending into the specimen. In Fig. 8 a sketch further explains the situation in the area of such a crack which will be referred to as a corner crack from hereon (for a geometrical description of a corner crack see e.g. [34]). The figure additionally shows how the crack length used in the diagrams was determined. The different stages

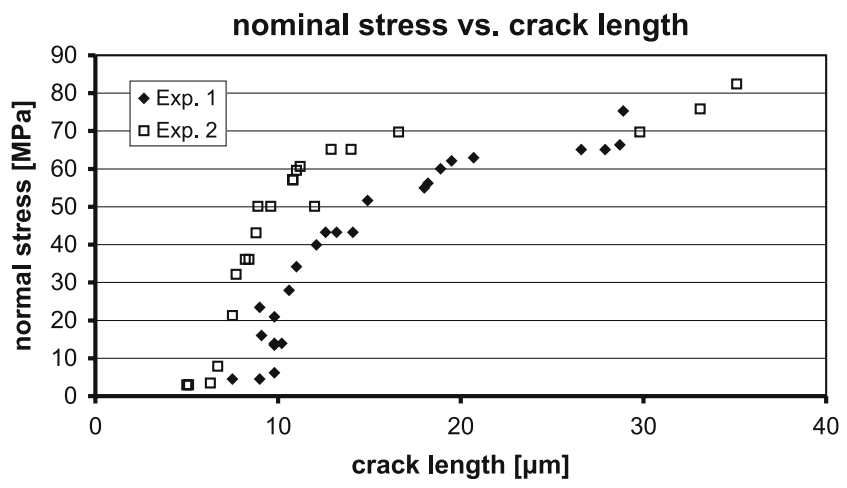

Fig. 5 Normal stress vs. crack length diagrams for the two conducted experiments. Both samples showed basically the same behaviour

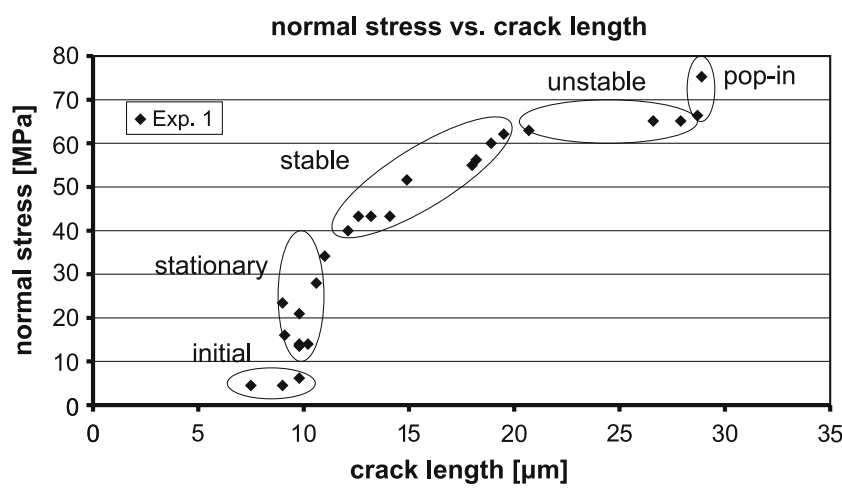

Fig. 6 The different stages during crack propagation. The terms are used according to [46]

of corner crack growth in the experiments herein are identified now:

- Initial crack length

For both samples there is an initial crack length even without external forces applied to the setup. In order to explain this situation, one has to take into consideration that during fabrication the compound of the silicon substrate and the polyimide layer is cooled down to room temperature after baking at $350^{\circ} \mathrm{C}$. Due to the large mismatch in the coefficients of thermal expansion between the two materials, high thermal tensile stresses develop in the polyimide layer. Furthermore, additional stress can develop in the surface layer due to solvent evaporation. After releasing the sample from the substrate during dry etching, these residual stresses are partially relieved as the sample is free to contract, partially close the initial crack and deform the silicon beams (see below). If during the experiment the samples are strained, the initial crack is opened again without applying any additional force. This explains why there is an apparent crack "growth" between the first two data points without any increase in external force and therefore nominal stresses. The fact why the residual stresses initially amount only to a few MPa and not to the number given for residual stress by the manufacturer (42 $\mathrm{MPa},[20])$ can be contributed to the aforementioned stress relief in the polyimide layer during dry etching. As the sample is freestanding after the etch step, it can contract and therefore reduce the residual stress until the residual force in the polyimide specimen is as large as the force necessary to deform the silicon beams to their initial position. Based on these thoughts the basic idea to 

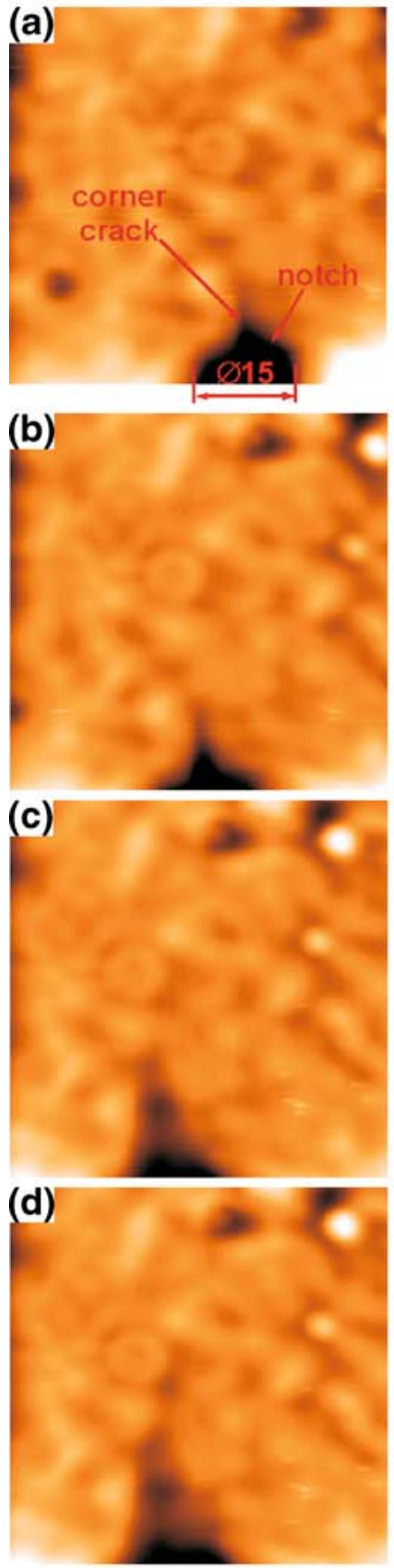

(e)
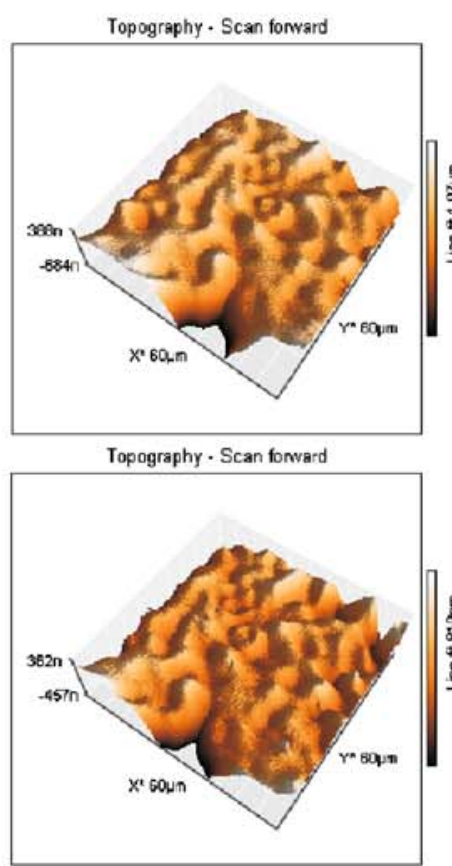

Topography · Scan fonward

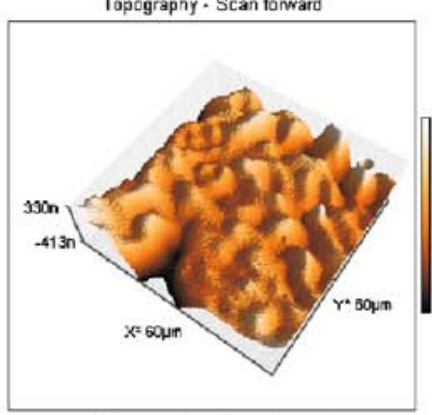

Topography - Scan forward

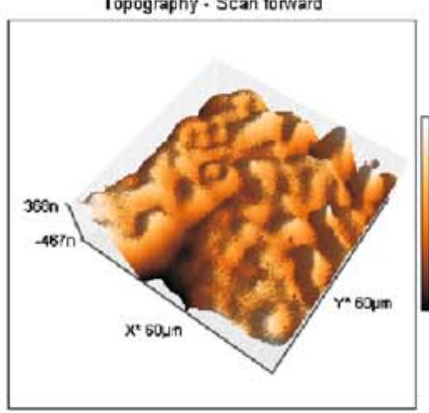

Topography - Scan forward

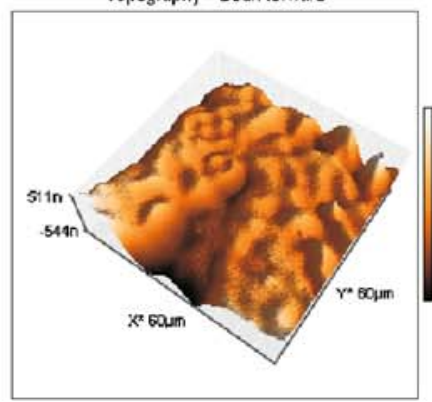

III

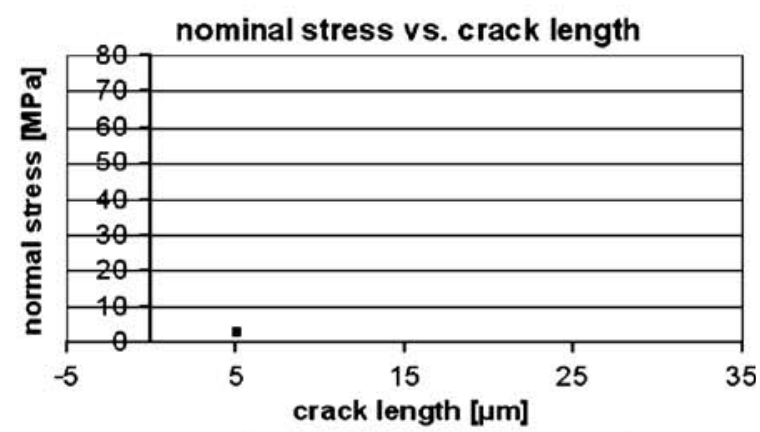

nominal stress vs. crack length

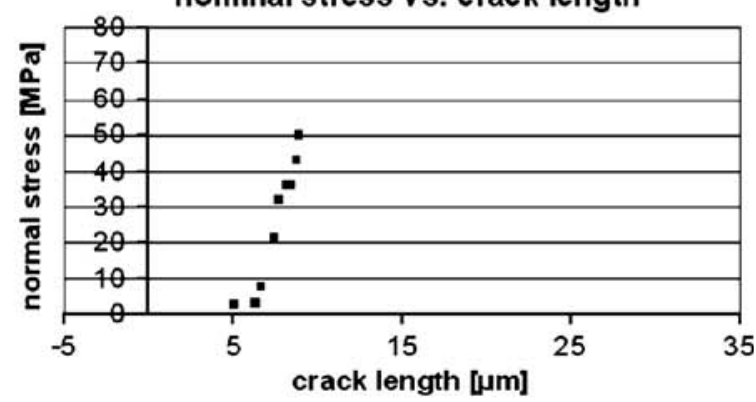

nominal stress vs. crack length

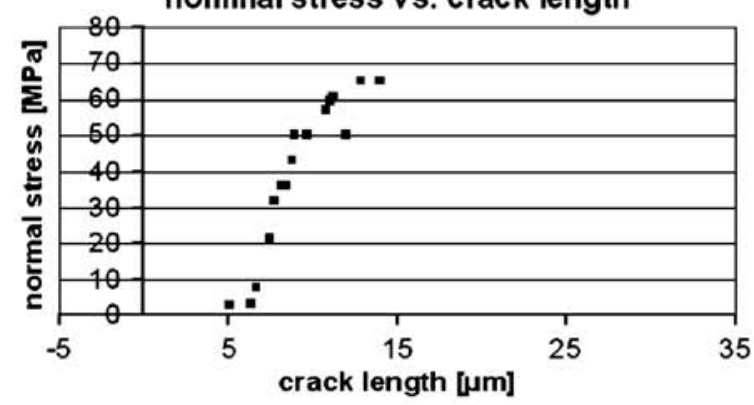

nominal stress vs. crack length

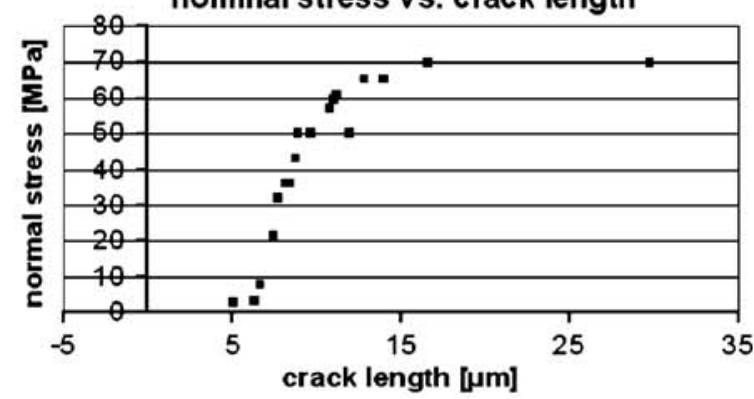

nominal stress vs. crack length

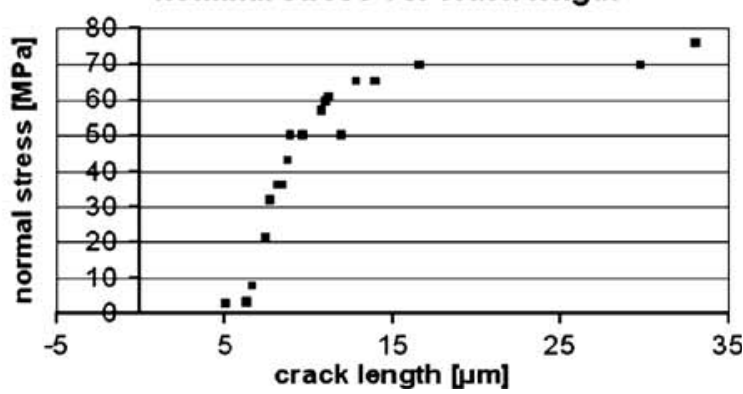


Fig. 7 Typical situations during crack propagation. Column I shows 2D scans with side lengths of $60 \mu \mathrm{m}$, column II are the corresponding 3D views and column III shows the stress-crack length diagrams. The AFM images always refer to the corresponding last data point of the diagrams. The stages of crack growth are: (a) initial crack length and initial notch radius in $\mu \mathrm{m}$, (b) stationary state i.e. no crack propagation at increasing stress, (c) stable crack growth, (d) unstable crack growth i.e. without increase of nominal stress the crack grows for a considerable distance and (e) before failure the crack growth is stopped again and a final increase of stress is necessary to initiate rupture. Note the appearance of material at the bottom of the crack for the last data points. This is an indication for a crack growing vertically and laterally from the corner of the top middle of the notch into the specimen

calculate the residual stresses is shown in Fig. 9. The balance of forces yields:

$$
\begin{aligned}
F_{\text {res }} & =F_{\text {res,dep }}-F_{\text {relief }} \\
& =\sigma_{\text {res,dep }} A-\frac{l_{0}-l_{1}}{l_{0}} E_{P I} A
\end{aligned}
$$

where $F_{r e s}$ is the force due to residual stresses during dry etching, $F_{\text {relief }}$ is the reduction of force due to stress relief by dry etching, $F_{\text {res,dep }}$ is the force due to residual stresses after deposition and before dry etching, $E_{P I}$ Young's modulus of PI 2723, $A$ is the cross sectional area of the specimen for calculating the nominal residual stress, $l_{0}$ is the length of the specimen after deposition and $l_{1}$ is the length of the specimen after dry etching. This initial length before the experiments can be calculated by

$l_{1}=l_{0}-\Delta f_{1}-\Delta f_{2}$

where $\Delta f_{i}$ are the deflections of the silicon beams as defined in Fig. 9. Assuming that $F_{\text {res }}$ is small compared to forces during the experiments, $\Delta f_{1}$

Fig. 8 Sketch demonstrating how a corner crack extends from the surface of the notch area into the material. It is also shown how the crack length as used herein was determined
Fig. 9 Determination of residual stresses: (a) after dry etching the residual stresses in the specimen are partially relieved but cause a deflection of the silicon beams, (b) free body diagram: the same force acts on the specimen and on the beams. To determine the force it is sufficient to measure the initial deflection $\Delta f_{2}$ of the force sensing beam, (c) $\Delta f_{2}$ can be determined by comparing the position of the force sensing beam before conducting the experiments and after rupture. In the sketches the lower beam is the force sensing beam while dashed lines show the initial position determined by photolithography

(a)

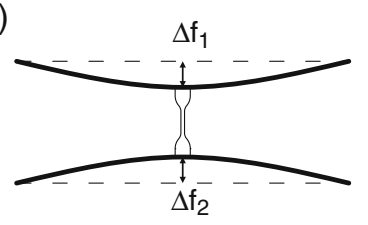

(b)
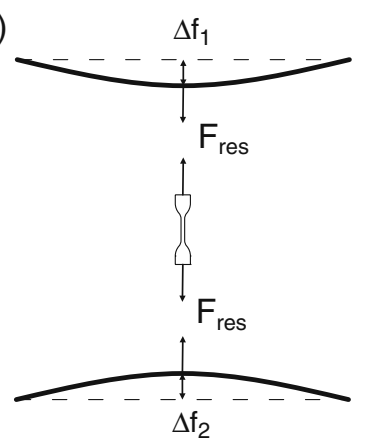

(c)

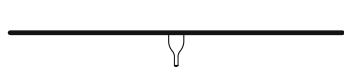

1

and $\Delta f_{2}$ can be calculated by using linear beam mechanics:

$\Delta f_{i}=\frac{F_{r e s} l_{S i, i}^{3}}{24 E_{S i} I}$

where $l_{S i, i}$ is the length of the respective silicon beam, $E_{S i}$ is the Young's modulus of silicon in $<110>$ direction and $I$ is the area moment of inertia for the silicon beams. Plugging in all known values into equation (7) and by using equations (8) and (9), a residual nominal stress $\sigma_{\text {res }}$ of $4.5 \mathrm{MPa}$ and a residual nominal stress after deposition $\sigma_{0}$ of 43.6 MPa could be determined for experiment 1 . This last value of $\sigma_{0}$ is in very good agreement with the value of $42 \mathrm{MPa}$ of residual stresses given by the manufacturer [20] for a $10 \mu \mathrm{m}$ thick layer of PI 2720 after deposition on a silicon wafer. As the residual stress is known, the stress state in the notch area can be estimated next. First the stress concentration factor for this particular situation has to be determined. As shown in Fig. 2 the depth of the notch is $48 \mu \mathrm{m}$. On the mask used for the lithography the notch is perfectly sharp while in reality it will become rounded due to reflow of the polyimide during baking. Figure 7(a) suggests that the corresponding radius is about $7.5 \mu \mathrm{m}$. This yields a ratio of notch radius to width of minimum cross section of $7.5 \mu \mathrm{m} / 143 \mu \mathrm{m} \approx 0.052$. Assuming furthermore a hyperbolically shaped notch the stress concentration factor can be obtained from charts given in $[35,36]$ to be $\approx 2.8$. The nominal 
stress in the smallest section of the specimen at the bottom of the notch is $43.6 \mathrm{MPa} \cdot 185 \mu \mathrm{m} / 143 \mu \mathrm{m} \approx$ $56.4 \mathrm{MPa}$. Multiplying this value with the stress concentration factor yields the stress in the bottom of the notch: $56.4 \mathrm{MPa} \cdot 2.8 \approx 158 \mathrm{MPa}$. This is in the order of the rupture strength of $160 \mathrm{MPa}$ given by the manufacturer [20] and therefore initial cracks after baking have to be expected.

- Stationary phase

The crack length remains stable while the external force is increased. The elastic energy stored in the material is not yet large enough to activate crack growth.

- Stable crack growth

The crack starts to grow and two very important observations can be made. Firstly, during crack opening no crazes can be found and secondly, material becomes visible at the bottom of the crack. This can also be seen in the three dimensional scans (Fig. 7). Therefore the assumption is that a crack growing vertically and laterally from the corner of the top middle of the notch into the specimen could be seen (see also Fig. 8).

- Unstable crack growth

The crack propagates vastly into the material without almost any additional load.

- Pop-in

The unstable crack growth is stopped shortly before final failure of the sample. Such a behaviour is normally called pop-in for macroscopic samples. This term will also be used here. In order to be able to stop a propagating crack plastic deformations need to take place to dissipate energy. Only from the AFM images such plastic processes could not be determined. After rupture the samples were

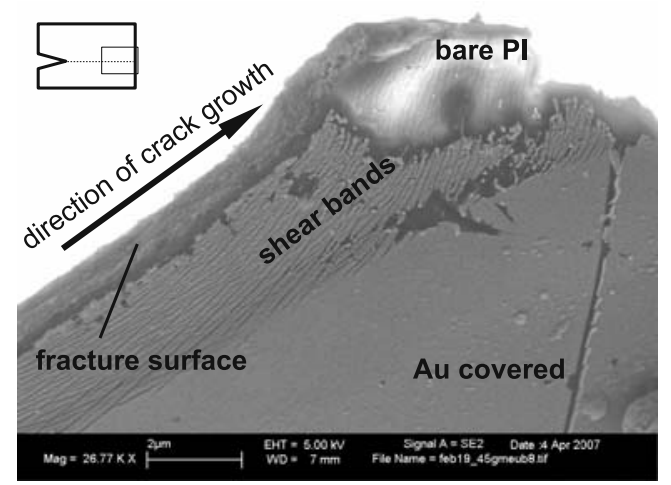

Fig. 10 SEM image of the vicinity of the crack. It shows the area opposite of the notch (see inset). The shear banded area grows due to increasing stresses with decreasing remaining cross sectional area. The sputtered gold layer partially came off and revealed the underlying patterns on the polyimide surface

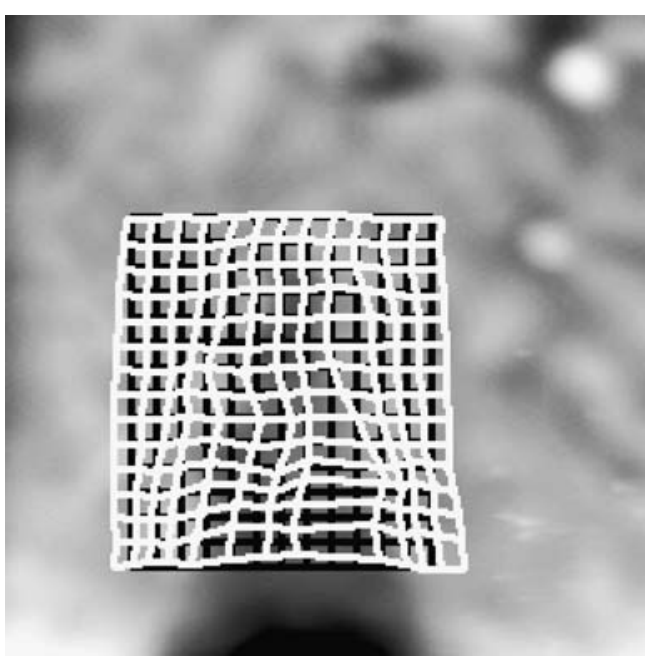

Fig. 11 Displacement field (white) at the crack tip obtained with the DIC software VEDDAC. It shows the state right before final rupture. The sidelength of the scan area is $30 \mu \mathrm{m}$

therefore first sputtered with approximately $10 \mathrm{~nm}$ of $\mathrm{Au}$ and then analyzed by scanning electron microscopy (SEM). Figure 10 shows how shear bands developed on the sample surface in the vicinity of the crack.

\section{Discussion}

In the previous section the experimental findings have been described. In this section a possible plastic deformation process for the pop-in effect is briefly presented. In general surface and corner cracks cause a multiaxial (three dimensional) and complicated stress state underneath the bottom of the crack [37, 38] as they disturb the uniaxial distribution of forces within the specimen. Only further away from the crack tip, the out-of-plane stress diminishes and therefore plane stress dominates. At room temperature and therefore far below $T_{g}$, the strongly entangled polymer chains prevent individual chains from reptating (Knaus, M, HD Microsystems Europe, Neu-Isenburg, Germany, personal communication, October 2008.). Therefore, void formation necessary for crazing is hindered and shear banding is favored [39, 40]. Additionally, if there is a high three dimensional stress level, chains are constrained by stresses in all directions and therefore brittle failure could occur [41]. Hence, it is assumed herein that chain scission is the failure mechanism in the area of triaxial stress i.e., while shear banding could occur in the area of plane stress i.e. in the vicinity of the crack. Such shear banding could in fact be observed by 
scanning electron microscopy (SEM) after rupture of the specimen as shown before in Fig. 10. This plastic deformation zone could therefore be the explanation of the pop-in behaviour and the resting of unstable crack growth. A detailed and in-depth discussion of the proposed deformation processes can be found in [42].

\section{Outlook}

While in these experiments only the crack length was determined, the application of digital image correlation (DIC) software could greatly enhance the possibilities of the setup. Figure 11 shows the results obtained by the DIC software package VEDDAC (Chemnitzer Werkstoffmechanik GmbH, Chemnitz, Germany). Not only could the crack tip opening displacement be observed, but also the displacement field ahead of the tip could in principle be analyzed. Both informations would be of great use in the application of fracture mechanics theories to the results and have partly already been reported in the literature for a resin polymer compact tension (CT) specimen [43]. Other examples in the literature on the determination of the displacement field around crack tips were based on AFM [16] or scanning tunneling microscopy (STM) [44], but without measurement of forces and stresses. Further improvements of the experiments seem to be possible by changing the layout of the PI specimens by applying rules set by Feddersen [45]. Instead of single notched specimens as used in this study, middle tension specimens with a defined ratio of notch length to specimen width could be used.

\section{Conclusions}

It was shown that the AFM could be used to observe crack growth with micrometer resolution in polyimide microspecimens. By applying beam mechanics to the deformation of a double fixed silicon beam connected to the specimen, forces in the range of millinewtons could be measured. This also allowed the simple determination of residual nominal stresses. By combining the two data sets of stresses and AFM scans the determination of stress-crack-length diagrams was possible. Different stages during crack growth could thus be identified. Combined with SEM images of the process zone, it was then possible to characterize the fracture and deformation behaviour of very thin polyimide layers. Finally, the potential of the method for future experiments with different geometries and the use of DIC software was discussed. These future steps might eventually lead to a reliable quantitative determination of fracture properties.

Acknowledgements The authors would like to express their gratitude to Prof. Bharat Bhushan from the Ohio State University, Prof. Taher Saif from the University of Illinois at Urbana-Champaign, Dr. Hans-Jakob Schindler from Mat-Tec AG (Winterthur, Switzerland), Dr. Pieter van Schendel from Nanosurf AG (Liestal, Switzerland), Dipl.-Ing. Bettina Seiler and Dr. Michael Dost from CWM GmbH (Chemnitz, Germany) and finally Dr. Nicola Naujoks from the Nanotechnology Group of ETH Zurich for very helpful discussions.

\section{References}

1. Chasiotis I, Knauss WG (2002) A new microtensile tester for the study of MEMS materials with the aid of atomic force microscopy. Exp Mech 42(1):51-57

2. Cho SW, Cardenas-Garcia JF, Chasiotis I (2005) Measurement of nanodisplacements and elastic properties of MEMS via the microscopic hole method. Sens Actuators A Phys 120(1):163-171

3. Cho SW, Chasiotis I (2007) Elastic properties and representative volume element of polycrystalline silicon for MEMS. Exp Mech 47(1):37-49

4. Chasiotis I, Cho SW, Jonnalagadda K (2006) Fracture toughness and subcritical crack growth in polycrystalline silicon. J Appl Mech 73(5):714-722

5. Cho SW, Jonnalagadda K, Chasiotis I (2007) Mode I and mixed mode fracture of polysilicon for MEMS. Fatigue Fract Eng Mater Struct 30(1):21-31

6. Lee Y, Tada J, Isono Y (2005) Mechanical characterization of single crystal silicon and UV-LIGA nickel thin films using tensile tester operated in AFM. Fatigue Fract Eng Mater Struct 28(8):675-686

7. Isono Y, Namazu T, Terayama N (2006) Development of AFM tensile test technique for evaluating mechanical properties of sub-micron thick DLC films. J Microelectromech Syst 15(1):169-180

8. Bobji MS, Bhushan B (2001) In situ microscopic surface characterization studies of polymeric thin films during tensile deformation using atomic force microscopy. J Mater Res 16(3):844-855

9. Tambe NS, Bhushan B (2004) In situ study of nano-cracking in multilayered magnetic tapes under monotonic and fatigue loading using an AFM. Ultramicroscopy 100(3-4):359-373

10. Li XD, Xu WJ, Sutton MA, Mello M (2006) Nanoscale deformation and cracking studies of advanced metal evaporated magnetic tapes using atomic force microscopy and digital image correlation techniques. Mater Sci Technol 22(7): 835-844

11. Nishino T, Nozawa A, Kotera M, Nakamae K (2000) In situ observation of surface deformation of polymer films by atomic force microscopy. Rev Sci Instrum 71(5):20942096

12. Opdahl A, Somorjai GA (2001) Stretched polymer surfaces: atomic force microscopy measurement of the surface deformation and surface elastic properties of stretched polyethylene. J Polym Sci Part B Polym Phys 39(19):2263-2274

13. Roggemann MC, Williams JG (2002) Use of an atomic force microscope to measure surface deformations in polymeric systems. J Adhes Sci Technol 16(7):905-920 
14. Bhushan B, Mokashi PS, Ma T (2003) A technique to measure poisson's ratio of ultrathin polymeric films using atomic force microscopy. Rev Sci Instrum 74(2):1043-1047

15. Bamberg E, Grippo CP, Wanakamol P, Slocum AH, Boyce MC, Thomas EL (2006) A tensile test device for in situ atomic force microscope mechanical testing. Precis Eng J Int Soc Precis Eng Nanotechnol 30(1):71-84

16. Li XD, Xu WJ, Sutton MA, Mello M (2007) In situ nanoscale in-plane deformation studies of ultrathin polymeric films during tensile deformation using atomic force microscopy and digital image correlation techniques. IEEE Trans Nanotechnol 6(1):4-12

17. Michler GH, Godehardt R (2000) Deformation mechanisms of semi-crystalline polymers on the submicron scale. Cryst Res Technol 35(6-7):863-875

18. Thomas C, Ferreiro V, Coulon G, Seguela R (2007) In situ AFM investigation of crazing in polybutene spherulites under tensile drawing. Polymer 48(20):6041-6048

19. Haque MA, Saif MTA (2002) In-situ tensile testing of nanoscale specimens in SEM and TEM. Exp Mech 42(1):123-128

20. LLC HD MicroSystems (1998) Pyralin PI2720 Processing Guidelines

21. Kajii H, Taneda T, Ohmori Y (2003) Organic light-emitting diode fabricated on a polymer substrate for optical links. Thin Solid Films 438:334-338

22. Lee JG, Seol YG, Lee NE (2006) Polymer thin film transistor with electroplated source and drain electrodes on a flexible substrate. Thin Solid Films 515(2):805-809

23. Tung S, Witherspoon SR, Roe LA, Silano A, Maynard DP, Ferraro N (2001) A MEMS-based flexible sensor and actuator system for space inflatable structures. Smart Mater Struct 10(6):1230-1239

24. Aslam M, Gregory C, Hatfield JV (2004) Polyimide membrane for micro-heated gas sensor array. Sens Actuators B Chem 103(1-2):153-157

25. Kuoni A, Holzherr R, Boillat M, de Rooij NF (2003) Polyimide membrane with $\mathrm{ZnO}$ piezoelectric thin film pressure transducers as a differential pressure liquid flow sensor. J Micromechanics Microengineering 13(4):S103-S107

26. ISO527-3 (1995) Plastics-determination of tensile propertiespart 3. Technical report

27. Lang U, Reichen M, Dual J (2006) Fabrication of a tensile test for polymer micromechanics. Microelectron Eng 83(49):1182-1184

28. Grellmann W (2005) Kunststoffprüfung, p 104. Carl Hanser Verlag, München

29. Ward IM (1983) Mechanical properties of solid polymers, 2nd edn, pp 83-84. Wiley, Chichester
30. Jones DRH, Ashby M (1998) Engineering materials, volume 2: an introduction to microstructure, processing and design, 2nd edn, p 238. Butterworth-Heinemann, Oxford

31. Popelar SF, Popelar CH, Kenner VH (1993) Time-dependent fracture of polyimide films. J Electron Packag 115:264-269

32. Frisch-Fay R (1962) Flexible bars, pp 83-91. Butterworths, London

33. Gerlach G (1997) Grundlagen der Mikrosystemtechnik, p 29. Carl Hanser Verlag, München

34. Anderson TL (1995) Fracture mechanics: fundamentals and applications, p 630. CRC, Boca Raton

35. Neuber H (1985) Kerbspannungslehre, pp 125-127. Springer, Berlin

36. Pilkey WD (1997) Peterson's stress concentration factors, p 65. Wiley, New York

37. Sommer E (1984) Bruchmechanische Bewertung von Oberflächenrissen, pp 28-35. Springer, Berlin

38. Sähn S, Göldner H (1989) Bruch- und Beurteilungskriterien in der Festigkeitslehre, p 32. VEB Fachbuchverlag Leipzig, Leipzig

39. Plummer CJG, Hedrick JL, Kausch HH, Hilborn JG (1995) Microdeformation in thin-films of $3 \mathrm{fda} / \mathrm{pmda}$ polyimide and polyimide nanofoams. J Polym Sci Part B Polym Phys 33(12):1813-1820

40. Jang BZ, Pater RH, Soucek MD, Hinkley JA (1992) Plasticdeformation mechanisms in polyimide resins and their semiinterpenetrating networks. J Polym Sci Part B Polym Phys 30(7):643-654

41. Donald AM, Kramer EJ (1982) The competition between shear deformation and crazing in glassy-polymers. J Mater Sci 17(7):1871-1879

42. Lang U (2008) Experimental methods for evaluating the mechanical properties of thin layers of intrinsically conductive polymers (Diss. ETH No. 17754). PhD thesis, ETH Zurich

43. Keller J, Vogel D, Schubert A, Michel B (2004) Displacement and strain field measurements from SPM images. In: Bhushan B, Fuchs H, Hosaka S (eds) Applied scanning probe methods, volume I of nanoScience and technology. Springer, Berlin Heidelberg New York, pp 253-276

44. Vendroux G, Schmidt N, Knauss WG (1998) Submicron deformation field measurements: part 3. Demonstration of deformation determinations. Exp Mech 38(3):154-160

45. Feddersen CE (1971) Evaluation and prediction of residual strength of center cracked tension panels. In: Rosenfield MS (ed) Damage tolerance in aircraft structures, volume ASTM STP 486. ASTM, Philadelphia, pp 50-86

46. Rösler J, Harders H, Bäker M (2003) Mechanisches Verhalten der Werkstoffe, p 141. BG Teubner, Stuttgart 